\title{
Development and Extension of An Aggregated Scale Model: Part 2 - Extensions to ASMITA
}

\author{
Ian TOWNEND ${ }^{\mathrm{a}}$, Zheng Bing WANG ${ }^{\mathrm{b}, \mathrm{c}}$, Marcel STIVE ${ }^{\mathrm{b}}$ and Zeng ZHOU ${ }^{\mathrm{d}}$ \\ a University of Southampton, Southampton SO17 1BJ, UK \\ ${ }^{\mathrm{b}} \mathrm{TU}$ Delft, Delft 2600 AA, The Netherlands \\ ' Deltares, Delft $2600 \mathrm{MH}$, The Netherlands \\ d Jiangsu Key Laboratory of Coast Ocean Resources Development and Environment Security, \\ Hohai University, Nanjing 210098, China
}

(Received 22 April 2016; accepted 16 May 2016)

\begin{abstract}
Whilst much attention has been given to models that describe wave, tide and sediment transport processes in sufficient detail to determine the local changes in bed level over a relatively detailed representation of the bathymetry, far less attention has been given to models that consider the problem at a much larger scale (e.g. that of geomorphological elements such as a tidal flat and tidal channel). Such aggregated or lumped models tend not to represent the processes in detail but rather capture the behaviour at the scale of interest. One such model developed using the concept of an equilibrium concentration is the Aggregated Scale Morphological Interaction between Tidal basin and Adjacent coast (ASMITA). In a companion paper (Part 1), we detail the original model and provide some new insights into the concepts of equilibrium, and horizontal and vertical exchange that are key components of this modelling approach. In this paper, we summarise a range of developments that have been undertaken to extend the original model concept, to illustrate the flexibility and power of the conceptual framework. However, adding detail progressively moves the model in the direction of the more detailed process-based models and we give some consideration to the boundary between the two.

Highlights

- A range of extensions to the original model ASMITA model are presented that allow additional processes or features to be represented in the model.

- The merits of ever increasing complexity within an aggregated model, versus the use of a suitable local-scale and more detailed process-based model are discussed.
\end{abstract}

Key words: estuary; tidal inlet; morphology; tides; waves; sediment transport

\section{Introduction}

The notion of an Aggregated Scale Morphological Interaction between Tidal basin and Adjacent coast (ASMITA) was first proposed by Stive et al. (1998) for the study of estuary and inlet response to sea level rise. The concepts that underpin the original development are detailed in Part $1-$ Background to ASMITA (Townend et al., 2016), together with additional discussion on the theoretical foundations of the method.

Whilst the initial model itself is a powerful tool, when seeking to understand the fundamental dynamics of inlets and estuaries, many features and processes were not included in the original formulation but have been added progressively over the last decade. These include such things as tidal pumping, saltmarsh elements, mixed sediments, variable surface area, littoral drift, and the influence of 
waves on the ebb-tidal delta.

Such developments all follow from the initial model formulation proposed by Stive et al. (1998) and elaborated in a number of subsequent papers (Kragtwijk et al., 2004; van Goor et al., 2003; Wang et al., 1998, 2008). In this paper, we detail these additions and characterise these different types of extension. The discussion then explores whether there are limits to the value of such extensions, in relation to alternative approaches, such as detailed process models. Equations and figures to be found in the accompanying paper are noted as in Part 1.

\section{Tidal Pumping}

For large macro-tidal estuaries, the equilibrium state can have a variable along-estuary concentration, from a relatively low value at the mouth to a maximum some distance into the estuary. This reflects flood dominance due to internally generated asymmetry in the tidal flow transporting sediment landward and ebb dominance due to the river flow moving sediment downstream. The convergence of the two gives rise to a turbidity maximum at some points in the estuary depending on the relative strength of the two influences. The landward mechanism has been characterised as tidal pumping (Friedrichs et al., 1998; Scully and Friedrichs, 2007; Yu et al., 2014) and can be thought of as an upstream directed discharge and associated sediment flux. For a convergent channel, the equations of mass continuity, momentum and the advection-dispersion are solved to obtain the net sediment flux, which can be expressed as (Friedrichs et al., 1998):

$$
J=\frac{3}{2} U c_{\mathrm{m}} \alpha^{\prime}\left[-\frac{u_{\mathrm{river}}}{U}+\frac{a_{\mathrm{eff}}}{h} k x-\frac{a_{2}}{a} \sin \theta_{2}+\frac{1}{4} \frac{T_{\mathrm{c}} U}{L_{\mathrm{w}}}\right],
$$

where, $J=$ net sediment flux over a tidal cycle, $a=$ amplitude of the dominant tidal frequency (usually M2 at mouth), $U=$ amplitude of the tidal velocity, $c_{\mathrm{m}}=$ concentration scale, $\alpha^{\prime}=$ coefficient for sediment mobilisation, $a_{2}=$ amplitude of the overtide and $\theta_{2}=$ phase of the overtide, $u_{\text {river }}=$ river flow velocity, $h=$ average depth of estuary, $x=$ distance from mouth of estuary, $L_{\mathrm{w}}=$ e-folding length of width convergence, $a_{\mathrm{eff}}=\left(H_{\mathrm{hw}}-H_{\mathrm{lw}}\right) / 2$, where $H_{\mathrm{hw}}$ and $H_{\mathrm{lw}}$ are hydraulic depths at high and low water respectively, $T_{\mathrm{c}}=$ adjustment time scale for the concentration field, $k=$ tidal wave number $=2 \pi / \lambda ; \sigma=$ $2 \pi / T_{\mathrm{p}} ; c=(g h)^{1 / 2}$ and $\lambda=c T_{\mathrm{p}}, T_{\mathrm{p}}$ being the tidal period.

For use in ASMITA we note that the river discharge is already handled (see section on advective flows in Part 1) and that concentration is defined locally for each element. We can therefore rewrite Eq. (1) as a discharge:

$$
q_{\mathrm{tp}}=\frac{3}{2} \alpha^{\prime} U A\left(\frac{a_{\mathrm{eff}}}{h} k x-\frac{a_{2}}{a} \sin \theta_{2}+\frac{1}{4} \frac{\sigma a}{w_{\mathrm{s}}}\right)-u_{\mathrm{river}} A\left(\frac{3}{2} \alpha^{\prime}-1\right) .
$$

This defines a discharge between two elements. For this to have any purpose within ASMITA, the channel needs to be represented by a number of elements (typically three or more) so that a gradient, defined by the competing river and tidal pumping discharges, can exist between elements. Including Eq. (2) leads to some additional terms in the sediment balance equations, as set out in the Appendix. The coefficient of sediment mobilisation, $\alpha^{\prime}$, has a default value of one. For a multi-element model, the 
along channel values of $\alpha^{\prime}(x)$ can be obtained by making use of the relation given by Friedrichs et al. (1998), where $u_{\text {river }}\left(x_{\text {turb }}\right)$ is the river velocity at the position of the turbidity maximum, defined as a distance from the mouth, $x_{\text {turb: }}$ :

$$
\alpha^{\prime}(x) \approx \exp \left[-\frac{2 u_{\text {river }}\left(x_{\text {turb }}\right)}{U^{2} T_{\mathrm{c}} L_{\mathrm{w}}}\left(x-x_{\text {turb }}\right)\right] .
$$

By specifying values of $\alpha^{\prime}(x)$ for each channel element, the model can be calibrated to ensure that the turbidity maximum occurs in the correct element.

Large estuaries with a significant river discharge, such as the Severn, Humber in the UK, Yangtze River in China and Scheldt in Belgium, are known to have a significant along-channel gradient in suspended sediment concentration. Nonetheless, these systems are considered to be stable and, when averaged over the long-term these gradients are persistent. Hence the forcing conditions and in particular the competing effects of river and tide must be maintaining a form of equilibrium, which in terms of concentration can be represented by the tidal pumping concept. The difference that this can make is illustrated using a model for the Severn estuary, with five channel elements and ten tidal flat elements. The results with and without tidal pumping are compared with some along channel measurements of suspended concentrations (Jonas and Millward, 2010) in Fig. 1, where there is a clear improvement in the modelled along-channel concentrations once tidal pumping is included.

Fig. 1. Comparison of suspended sediment concentrations in the Severn Estuary against model concentrations with and without the inclusion of tidal pumping.

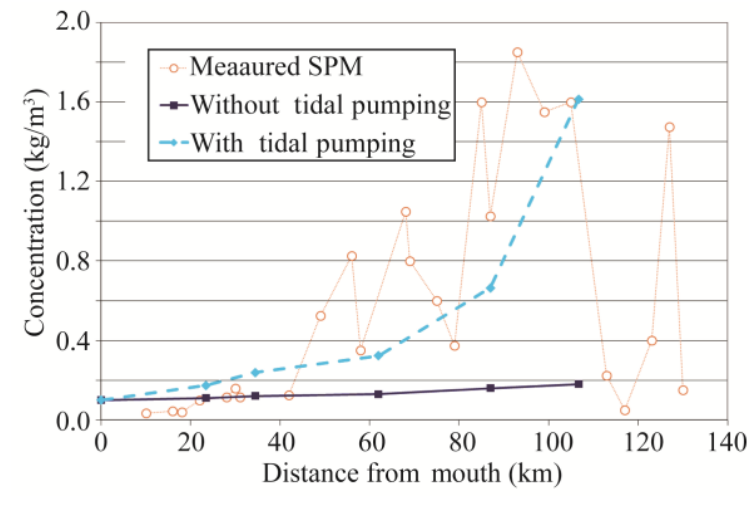

\section{Saltmarsh and Storage Elements}

Two additional types of element can be readily added; one to include saltmarsh and the other to include areas of tidal storage outside the existing banks of the estuary (this is commonly used for managed realignment projects in Europe and the USA (Townend et al., 2010b).

\subsection{Saltmarsh Elements}

An important extension, especially if the surface area is allowed to vary (see below), is to take account of the stabilising effect of saltmarsh, the trapping of sediment and the feedback this provides to concentrations in the rest of the system. One way of doing this is to introduce a saltmarsh element in which specific account is taken of the biological contribution to sedimentation (Knaapen et al., 2009). This is usually described as comprising an inorganic and an organic component, although the former is 
often broken down into a more detailed representation. For instance, the enhanced inorganic settling can be considered to be the result of modifying the flow conditions within the canopy, and trapping of the sediment by the vegetation (Mudd et al., 2004). Here we use the marsh depth, $D$, as a surrogate for the hydroperiod as proposed by Morris et al. (2002), with biomass production also defined as a function of marsh depth.

$$
\frac{\mathrm{d} z}{\mathrm{~d} t}=\left[q_{\mathrm{m}}+\Sigma(k B)\right] D \quad \text { and } \quad B_{i}=a_{i} D+b_{i} D^{2}+c_{i} .
$$

In this equation, Morris defines $q_{\mathrm{m}}$ and $k$ as proportional to the rate of sediment loading and the efficiency of the vegetation as a sediment trap, although he notes that $k$ includes the influence of organic sedimentation. The biomass productivity, $B$, is described for each species, $i$, by three coefficients $a_{i}, b_{i}$ and $c_{i}$. If the upper and lower limits of a species and the magnitude of the peak biomass are known, the values of the coefficients can be determined. For a marsh in equilibrium, the rate of change of marsh elevation has to equal the long-term rate of change of sea level, $\zeta$. This leads to a cubic equation in $D$, where the smallest real positive root is the stable depth and the larger root is unstable against perturbation (Morris et al., 2002).

$$
\sum_{i} k_{i}\left(b_{i} D^{3}+a_{i} D^{2}+c_{i} D\right)+q_{\mathrm{m}} D-\frac{\mathrm{d} \zeta}{\mathrm{d} t}=0 .
$$

The settling and trapping contributions are combined and treated as enhancements to the rate of vertical settling, and the organic contribution is then added, and Eq. (4) becomes:

$$
\frac{\mathrm{d} z}{\mathrm{~d} t}=w_{\mathrm{s}}^{\prime} c+\sum_{i}\left(k_{\mathrm{b}} B\right) D
$$

Here $w_{\mathrm{s}}{ }^{\prime}=f\left(w_{\mathrm{s}}, B\right)$ is an enhanced vertical fall velocity that reflects the additional dissipation of the kinetic energy due to the vegetation and the influence of trapping (both of which depend on the size and density of the vegetation and hence are a function of biomass) and $c$ is the sediment concentration in the water column. The second term represents the organogenic contribution, where $k_{\mathrm{b}}$ is a rate coefficient, and the enhanced settling velocity can be posed as the combined influence of settling and trapping:

$$
\left\{\begin{array}{l}
w_{\mathrm{s}}^{\prime}=w_{\mathrm{s}}+\alpha\left(\sum_{i} \frac{B_{i}}{B_{\max , i}}\right)^{\beta} D \quad \text { when } \quad c \leq c_{\mathrm{e}} \\
w_{\mathrm{s}}^{\prime}=w_{\mathrm{s}} / T_{\mathrm{sn}} \\
\text { when } c>c_{\mathrm{e}}
\end{array}\right.
$$

where $B_{\max , i}$ is the maximum biomass for the species and the coefficients $\alpha$ and $\beta$ scale the relative biomass to give the appropriate variation in enhanced settling rate. The condition relative to the local equilibrium concentration, $c_{\mathrm{e}}$, reflects the fact that enhanced settling will only take place when the element is importing sediment (i.e. accreting). When exporting sediment (i.e. erosion) the specified value of vertical exchange is divided by the duration of the spring-neap cycle, $T_{\mathrm{sn}}$, to reflect the much slower rate of erosion of the marsh surface, due to the duration of exposure and the protective influence of the vegetation. With the data currently available, it is usually necessary to adopt typical values from the literature and then adjust the parameters to match the observed long-term change.

We now relate Eq. (6) to the rate equation used in ASMITA and note that the first term is similar 
to the form used to consider the rate of change of the water volume in an element, and with $V=D S$, Eq. (6) can be written as:

$$
\frac{\mathrm{d} V}{\mathrm{~d} t}=w_{\mathrm{s}}^{\prime} S\left(c_{\mathrm{e}}-c\right)-\sum_{i}\left(k_{\mathrm{b}} B\right) V
$$

Note: the sign of the term $\sum\left(k_{\mathrm{b}} B\right) D$ is taken to be negative as deposition of organic material to the bed will reduce the water volume, as does the first term when $c>c_{\mathrm{e}}$, where $c$ is the concentration and $c_{\mathrm{e}}$ the local equilibrium concentration. Rather than use a relationship between volume and tidal prism, as used for channels and flats, equilibrium is based on the equilibrium depth for a given rate of sea level rise, Eq. (5), and the plan area of the marsh. The value of $q_{\mathrm{m}}$, in Eq. (5) can either be specified, or an estimate of the sediment loading based on settling and trapping fluxes:

$$
q_{\mathrm{m}} D=Q_{S}+Q_{T}=w_{\mathrm{s}}^{\prime} \frac{1}{T} \int c \mathrm{~d} t
$$

where the sedimentation concentration over the marsh, $c$, is determined using the method proposed by Krone (1987) and modified to include the instantaneous trapping flux by Marani et al. (2007) and the integration is over a suitable interval, $T$, such as a tidal cycle or a spring-neap cycle.

To include saltmarsh as an element within ASMTIA it is necessary to define the equilibrium area and volume (or just the volume for the fixed area case). One approach is to make use of the idealised form model that can also be used as an equilibrium condition (see section on idealised cross-section as a function of tidal prism in Part 1), to define the unvegetated profile. The portion of this profile to landward of the maximum depth that any species can tolerate is assigned to the saltmarsh and the area seawards to the flat element. The equilibrium depth, Eq. (5), times the surface area gives the water volume over the marsh. Where actual values of marsh area and volume are available, these idealised estimates can be scaled by the ratio of the known value to the theoretical value, so that they can be related to changes in the system as a whole.

The effect of introducing several species appears to be complex, and depends on the interaction between species: if multiple species can coexist they may increase the resilience to sea level rise by increasing biomass and therefore sediment trapping and biological production (Morris, 2006). However, if adding more species gives a lower overall biomass, because the presence of more species makes the depth conditions less optimal for other species, then resilience to sea level rise may be lowered. This depends on the characteristics of the species present and their ability to thrive under the deeper conditions created by sea level rise and the prevailing sediment loading (Townend et al., 2010a).

To illustrate the influence of saltmarsh on system behaviour, a saltmarsh element is added to the Humber model so that it comprises of a channel, flat and saltmarsh. The simulations presented are for the case where there is no saltmarsh present and a saltmarsh with three species. With no saltmarsh species present, the saltmarsh element still exists as a separate element to the flat, but its behaviour is the same as for the flat. Saltmarsh in the Humber is dominated by Puccinellia maritima and Halimione portulacoides, with the lower marsh being comprised almost exclusively of Spartina anglica. A MHWN of $1.6 \mathrm{mOD}$ (Mean High Water Neaps measured in metres above Ordnance Datum) was used with a tidal range of $5.84 \mathrm{~m}$, together with the saltmarsh parameters given in Table 1. The sea level 
changes at a rate of $2 \mathrm{~mm} / \mathrm{a}$ for the first 300 years and then accelerates exponentially to a rate of almost $20 \mathrm{~mm} / \mathrm{a}$ over the next 200 years (this illustrates the sort of change projected in the IPCC reports). These plots also include the influence of variable surface area (see below) and a constraint at high water (such as a sea wall).

Table 1 Saltmarsh properties used in three element model of the Humber as illustrated in Fig. 2

\begin{tabular}{lcccccc}
\hline \multicolumn{1}{c}{ Species } & $\begin{array}{c}\text { Min. depth } \\
\text { factor }\end{array}$ & $\begin{array}{c}\text { Max. depth } \\
\text { factor }\end{array}$ & $\begin{array}{c}\text { Min. depth } \\
(\mathrm{m})\end{array}$ & $\begin{array}{c}\text { Max. depth } \\
(\mathrm{m})\end{array}$ & $\begin{array}{c}\text { Max. biomass } \\
\left(\mathrm{kg} / \mathrm{m}^{2}\right)\end{array}$ & $\begin{array}{c}\text { Biogenic } \\
\text { production rate } \\
k_{\mathrm{bm}}\left[\mathrm{m}^{2} /(\mathrm{kg} \cdot \mathrm{a})\right]\end{array}$ \\
\hline Spartina & 1.7 & 1.20 & 0.20 & 1.00 & 0.8 & 0.020 \\
Puccinellia & 1.9 & 1.50 & 0.00 & 0.52 & 1.5 & 0.002 \\
Halimione & 1.9 & 1.55 & -0.12 & 0.44 & 1.7 & 0.002 \\
\hline
\end{tabular}

Note: Some authors give the depth range as a function of tidal range, using a depth factor, $\kappa$, of the MHWN elevation, $z_{M H W N}$, so that the depth is given by $D=a-\kappa z_{M H W N}$, where $a$ is the tidal amplitude (columns 2 and 3) whereas others simply give depth over the marsh (columns 4 and 5).

The influence of the presence of saltmarsh is clearly seen in the changes in volume and surface area of the three elements shown in Fig. 2.
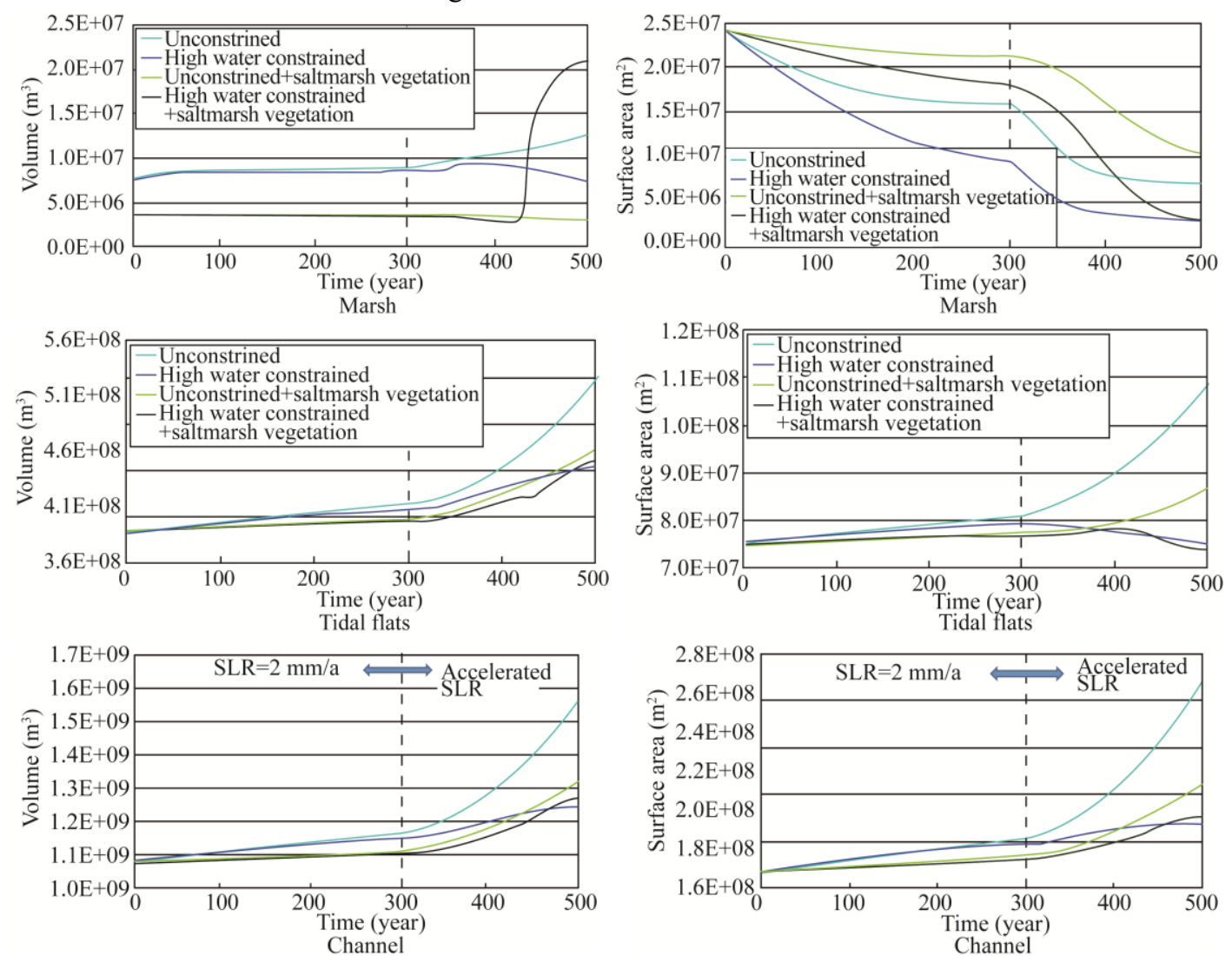

Fig. 2. Changes is volume and surface area of the channel, flat and marsh to illustrate the influence of changing rates of sea level rise on the ability of the marsh to adapt and the significance of the role of constraints at high water when the system is allowed to adjust the surface area as well as the volume. 
With a relatively low rate of sea level rise the marsh is able to maintain an equilibrium depth and the volume and surface area change little. However, as sea level rise begins to accelerate, from year 300 onwards, whether the marsh is able to keep up depends on the constraints. For a system that is unconstrained and has no marsh, the flat and channel expand in volume and area, reflecting the increase in tidal prism. Introducing a constraint at high water limits the change in area but not volume so the channel and flat get deeper. With the introduction of vegetation, the system is a lot more stable if unconstrained, so that the marsh can extend landwards as sea level rises. However, if the system is constrained at high water, this can lead to the sudden disappearance of the vegetation as the marsh drowns. This highlights the importance of vegetation along the fringes of channels and creeks in limiting the rapid expansion of the system under the influence of sea level rise.

\subsection{Storage Elements}

Storage elements are typically linked to a channel or tidal flat and have the effect of increasing the total prism of the estuary and potentially affecting downstream elements. The vertical and horizontal exchange for storage elements are defined in the same way as for other elements. Hence, given their usual location landward of the tidal flats, if a mixed sediment model is used, parameters based on fine sediments are often the most appropriate (see next section). Based on the evidence currently available for managed realignment schemes in Europe (Scott et al., 2011), this type of storage area has one or more inlets (often made by breaching the existing sea wall) and the internal form is largely the flooded landscape. Just how to define the new equilibrium for this sub-system requires further research. The approach adopted to-date is to either assume a volume to prism ratio, or define a hypsometry based on historical evidence (Townend, 2008) and use the method outlined in Part 1 to couple the hypsometry with the tidal prism.

\section{Mixed Sediments}

Another important influence on the morphological evolution of tidal basins is the sediment characteristics of both the sea bed and the available sources that supply sediment (marine and fluvial). Some account can be taken of spatial variations by using different vertical exchange properties for elements and, importantly, varying the bed density of elements. However, within estuaries and inlets there is often a marked difference between the sediments within different parts of the system. Quite often there is hardly any mud to be found within the channels and ebb-tidal delta, whereas the tidal flats are predominantly composed of fine sediments and muds (Zhou et al., 2015).

By making some assumptions about the nature of change it is possible to introduce a mud fraction into ASMITA (Wang et al., 2014). Rather than tracking the various fractions and distinguishing between differing deposition and erosion rates, we assume that conditions prevail that favour deposition of the fine fraction on the intertidal but not in the channels or on the ebb-tidal delta. Under conditions of (accelerated) sea level rise this is considered to be a reasonable assumption. Hence we only need to consider the mud fraction for tidal flat elements. In addition, as only erosion is influenced by the (change of) bottom composition, it is not necessary to undertake book keeping of sand and mud contents in the bottom layers. The mud and sand fraction can thus be implemented in parallel without 
any interaction between the two. Therefore, the ASMITA model is extended by a simplified implementation of the effect of mud transport on the morphological changes of the tidal flat element, derived based on the single element model formulation with only mud as:

$$
\left.\frac{\partial V}{\partial t}\right|_{\mathrm{m}}=w_{\mathrm{m}} c_{\mathrm{EM}} S_{\mathrm{f}} \frac{\delta_{\mathrm{m}}}{\delta_{\mathrm{m}}+w_{\mathrm{m}} S_{\mathrm{f}}}\left[1-\left(\frac{V_{\mathrm{f}}}{V_{\mathrm{fe}}}\right)^{n_{\mathrm{m}}}\right]=w_{\mathrm{m}} c_{\mathrm{m}} S_{\mathrm{f}}\left[1-\left(\frac{V_{\mathrm{f}}}{V_{\mathrm{fe}}}\right)^{n_{\mathrm{m}}}\right],
$$

where the subscript ' $m$ ' denotes the mud fraction and "f" denotes the tidal flat element. From this equation it follows that the global and local mud concentrations, $c_{\mathrm{EM}}$ and $c_{\mathrm{m}}$ respectively, are related as follows:

$$
c_{\mathrm{EM}}=\frac{c_{\mathrm{m}}}{\delta_{\mathrm{m}}}\left(\delta_{\mathrm{m}}+w_{\mathrm{m}} A_{\mathrm{f}}\right) .
$$

We also note that for given hydrodynamics and the condition given by Eq. (9) in Part 1, the horizontal and vertical exchanges should be related as follows:

$$
\frac{\delta_{\mathrm{m}}}{\delta_{\mathrm{s}}}=\frac{w_{\mathrm{s}}}{w_{\mathrm{m}}} .
$$

To implement a mud fraction for intertidal elements, the following parameters need to be assigned:

- $\quad$ an appropriate transport coefficient (typically a value closer to five characteristic of suspended sediment transport);

- a suitable vertical exchange coefficient that reflects the sediment size, concentration and the influence of flocculation; and

- $\quad$ a horizontal dispersion, adjusted in line with Eq. (12).

To illustrate the influence of bed density and the inclusion of a mud fraction, the ASMITA model was applied to the Amelander Zeegat, a tidal inlet in the Dutch Wadden Sea, examined by van Goor et al. (2003). The parameters have been updated following the procedure for model calibration outlined above (Wang et al., 2008) to give the settings detailed as case (i) in Table 2. This case was run with and without sea level rise (the rate used when included was $6 \mathrm{~mm} / \mathrm{a}$ ), as shown in Fig. 3.

Table 2 Parameters used in the Amlander Zeegat model to investigate the influence of bed density and mixed sediment (sand-mud fractions) as used for cases shown in Fig. 3.

\begin{tabular}{lccccc}
\hline \multicolumn{1}{c}{ Case } & $\begin{array}{c}\text { Bed density } \\
\left(\mathrm{kg} / \mathrm{m}^{3}\right)\end{array}$ & $\begin{array}{c}\text { Equilibrium } \\
\text { concentration }\left(\mathrm{kg} / \mathrm{m}^{3}\right)\end{array}$ & $\begin{array}{c}\text { Transport } \\
\text { coefficient }\end{array}$ & $\begin{array}{c}\text { Vertical exchange } \\
(\mathrm{m} / \mathrm{s})\end{array}$ & $\begin{array}{c}\text { Horizontal } \\
\text { exchange }\left(\mathrm{m}^{3} / \mathrm{s}\right)\end{array}$ \\
\hline (i) Base case & 2650 & 1.06 & 5 & 0.01 & $300 / 300 / 200$ \\
(ii) Include bed density & 2000 & 0.64 & 5 & 0.01 & $300 / 300 / 200$ \\
$\begin{array}{l}\text { (iii) Variable bed density } \\
\begin{array}{c}\text { (iv) Variable bed density } \\
\text { and mixed sediments }\end{array}\end{array}$ & $2000 / 2000 / 1600$ & 0.64 & 5 & 0.01 & $300 / 300 / 200$ \\
$\begin{array}{c}\text { (v) as case (iv) with } \\
\text { different } c_{\mathrm{EM}}\end{array}$ & $2000 / 2000 / 1600$ & $\begin{array}{c}c_{\mathrm{ES}}=0.64 ; c_{\mathrm{EM}}=0.64 \\
r=1\end{array}$ & $5 / 5 / 3$ & $0.01 / 0.01 / 2 \mathrm{e}-4$ & $300 / 300 / 10000$ \\
$\begin{array}{c}\text { (vi) as case (iv) with } \\
\text { different } c_{\mathrm{EM}}\end{array}$ & $2000 / 2000 / 1600$ & $\begin{array}{c}c_{\mathrm{ES}}=0.64 ; c_{\mathrm{EM}}=0.4 \\
r=0.62\end{array}$ & $5 / 5 / 3$ & $0.01 / 0.01 / 2 \mathrm{e}-4$ & $300 / 300 / 10000$ \\
\hline $\begin{array}{c}c_{\mathrm{ES}}=0.64 ; c_{\mathrm{EM}}=0.2 \\
r=0.31\end{array}$ & $5 / 5 / 3$ & $0.01 / 0.01 / 2 \mathrm{e}-4$ & $300 / 300 / 10000$ \\
\hline
\end{tabular}

Note: where only a single value given this was used for all three elements. Where three values are given these are for delta, channel flat, respectively and horizontal exchanges are from outside-delta, delta-channel and channel-flat.

The base case was then modified by adjusting the bed density for all elements and adjusting the 
global equilibrium concentration, $c_{\mathrm{E}}$. This case (ii) is not shown in Fig. 3 because it is identical to case (i) with sea level rise. The bed density of the tidal flat was then further reduced to a more realistic value for a mud flat and is shown as case (iii) on Fig. 3. In the next three cases, the mud parameterisation is adopted and Eq. (42) in Part 1 is applied to the tidal flat element. In these three runs the global mud concentration is progressively reduced from a value equal to $c_{\mathrm{ES}}$ (case (iv): $r=c_{\mathrm{EM}} / c_{\mathrm{ES}}=1$ ) to a value of $0.2 \mathrm{~kg} / \mathrm{m}^{3}$ (case(vi): $r=0.31$ ). The three values of $c_{\mathrm{EM}}$ used equate to local concentrations, $c_{\mathrm{m}}$, of $0.14,0.088$ and $0.044 \mathrm{~kg} / \mathrm{m}^{3}$ and a value of around 0.1 has been observed on the flats. The model is clearly sensitive to both bed density and the equilibrium concentration used for mud and sand. This could, however, be particularly important in inlets that have been deepened and the balance of mud and sand is altered and certainly merits further research.

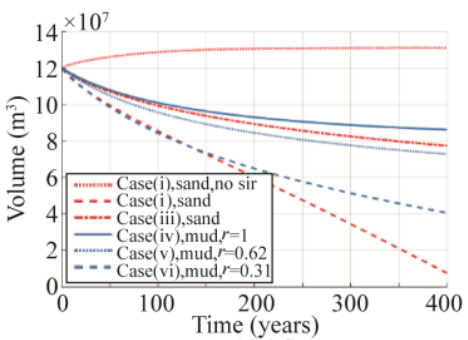

(a) Tidal flat

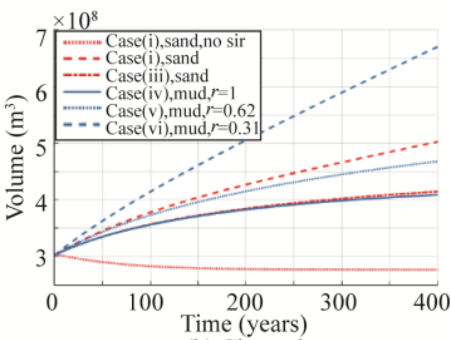

(b) Channel

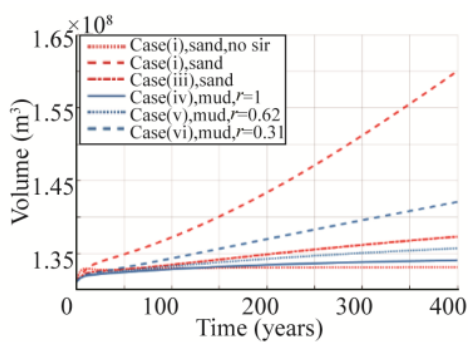

(c) Delta

Fig. 3. Results from a three element model (channel, flat and delta) with a tidal flat of wither sand or mud, varying bed density and different equilibrium mud concentrations (see Table 2 for parameters used for each case).

\section{Variable Surface Area and Constraints}

As estuaries vary throughout their length, the change in depth is generally much smaller than the change in width. A corollary of this statement is that the tidal, wave, fluvial and geotechnical effects that define an estuary geometry induce much larger changes to the width of a cross-section than to the depth. In addition, the downstream part of an estuary, which is predominantly tidal, tends to experience less proportional change in depth with distance than the head of an estuary which is much more affected by fluvial discharges. Since the volume and surface area within an estuary tend to be dominated by the much wider and deeper downstream reaches, estuary volume tends to correlate highly with surface area. Indeed, for UK estuaries one of the strongest observed correlations is between the surface area at mean tide level and the tidal prism (Townend, 2005). This suggests that a relationship similar to Eq. (1) in Part 1 can be written for the water surface area of an element and a similar approach used to derive the temporal variation in area.

One of the options for defining equilibrium uses the link between basin hypsometry and tidal prism (see Part 1). Variations in volume with elevation are monotonic (Part 1, Fig. 3) and can be described as a nonlinear function of relative depth, such as Eq. (31) in Part 1 (Wang et al., 2002). Differentiating the volume leads to an expression for the surface area, Eq. (33) and Fig. 3 in Part 1.

Following the approach adopted for volumes, Eqs. (1)-(6) in Part 1, and assuming a uniform vertical profile of discharge and concentration, the horizontal flux between elements at some elevation, $z$, is given by: 


$$
J_{i, j}=\frac{q_{i, j}}{h_{j}} \cdot c_{i}+\frac{\delta_{i, j}}{\hat{h}_{i, j}}\left(c_{i}-c_{j}\right),
$$

where $\hat{h}$ is the average height of the interface between elements and $h_{j}$ is the average depth of the element the flux is moving into. Generally, it will be reasonable to take the interface height as the average depth of the two elements, i.e. $\left(h_{i}+h_{j}\right) / 2$. Similarly, in the vertical we have:

$$
J_{z i}=\frac{w_{i} S_{i}}{h_{i}}\left(c_{i \mathrm{e}}-c_{i}\right)
$$

where $h_{i}$ is the average depth of the element, typically given by $V / S$. If the exchange parameters are normalized as function of depth:

$$
\hat{q}=\frac{q}{h} ; \quad \hat{\delta}=\frac{\delta}{\hat{h}} \quad \text { and } \quad \hat{w}=\frac{w}{h} .
$$

The nonlinear equations describing the variation in surface area for a single element are therefore similar to the equations for volume (Eq. (6) in Part 1), with the tidal prism scaled as a function of tidal range, $t r$ :

$$
\left\{\begin{array}{l}
S_{\mathrm{e}}(t)=\hat{\alpha} \cdot \frac{P}{t r}=S_{o}+\hat{\alpha} \cdot \frac{P_{0}+\Delta P}{t r} \\
S_{\mathrm{f}}(t)=S_{\mathrm{f} 0}+\int \frac{\mathrm{d} S}{\mathrm{~d} t} \mathrm{~d} t \\
S_{\mathrm{m}}(t)=S_{\mathrm{m} 0}+\int \frac{\mathrm{d} S}{\mathrm{~d} t} \mathrm{~d} t+R \int \frac{\mathrm{d} \zeta}{\mathrm{d} t} \mathrm{~d} t
\end{array}\right.
$$

When considering fixed areas, the high and low water surface areas are typically used to define the spatial extent of elements such as channel and tidal flat. The above equations provide a means of estimating how these areas might change over time. Clearly, if unconstrained, changes at high water imply a change in the overall size of the basin. To enable any element to expand beyond its initial domain, the parameter $R$ represents the change in area for a unit change in water level and is given by $R=n_{\mathrm{bk}} \cdot m_{\mathrm{b}} L$, where $n_{\mathrm{bk}}$ is the number of bed surfaces in the element (generally two for the two sides of the estuary), $1: m_{\mathrm{b}}$ is the transverse bed slope at the upper water surface of the element and $L$ is the length of the element. For multiple elements, Eq. (16) can again be written in matrix form (see Appendix).

Hence varying surface area can be coupled with varying volume by substituting the surface area obtained from Eq. (16) into the equation for volume, Part 1, Eq. (6), at each time step. The equilibrium surface area is obtained in a similar way to the equilibrium volume, using one of the various approaches outlined in Part 1.

The influence of allowing the surface area to vary can be seen in Fig. 2. As the tidal prism is increased in response to sea level rise, there is a positive feedback and a further increase in prism due to the expansion of the estuary area. This makes clear the importance of the constraints around the estuary margins, such as vegetation, cliffs, sea walls, etc. A multi-element model of the Humber, comprising a delta and a series of seven channel and seven tidal flat elements, was used to examine historical behaviour (Townend et al., 2008). The historical data clearly identifies the nodal cycle, 
particularly in the variation of water volumes (Jeuken et al., 2003), Part 1, Fig. 5, however such a variation is also present in the surface areas as shown in Fig. 4. This compares the historical data with model results for the unconstrained case and a case with the high water area limited by the influence of sea walls. From this data set, the latter appears to be providing the better fit, which is reasonable given that the estuary has been subject to extensive reclamation and enwalling of marshes since the 18th century. An assessment of the individual elements also suggests that a better agreement is achieved when high water constraints are included.

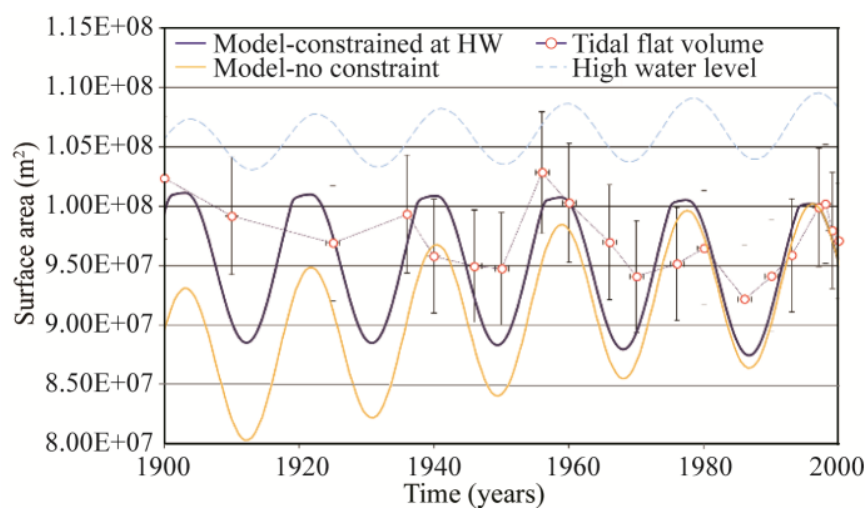

Fig. 4. Comparison of modelled intertidal surface area with historical data from the Humber Estuary. Measured data includes error bars ( \pm 1 year and $\pm 5 \%$ volume or area). See Fig. $5(\mathrm{~b})$ in Part 1 for equivalent volume changes.

When the overall area of the system is constrained (e.g. HW area is fixed) this provides a constraint on the elements within the system even if they are allowed to vary in area. An alternative to the above approach might therefore be some simple rules to redistribute the area between elements at each time step. For example:

Step 1: calculate potential change of area for each element based on relative change of volume.

Step 2: calculate the shift (e.g. between channel and flat) by weighted averaging the potential area changes (taking into account the sign of changes).

For unconstrained cases, a similar procedure could be followed but first the expansion of the total area needs to be calculated. This requires some information about the accommodation space into which the estuary moves such as the topography of the flood plain (as represented by the aggregated slopearea parameter, $R$, in Eq. (18).

\section{Delta and Littoral Drift}

The original formulation of ASMITA includes a tidal delta element, which can be represented within the framework defined by Eqs. (1)-(6) as outlined in Part 1, with a suitable equilibrium relationship for a tidal delta. However, this considers the inlet or estuary as an isolated unit rather than linked to the adjacent coast. To take account of littoral drift, or to link ASMITA to a shoreline model, such as a one-line beach model (Zhou et al., 2013), the alongshore sediment transport need to be included as an input to and output from the tidal delta.

Given some input littoral drift, the output drift to the downdrift shore has to be calculated. Several 
models have been proposed that subdivide the delta into a number of components and adopt a sediment balance between elements that is similar to the approach used within ASMITA (de Vriend et al., 1994; Kraus, 2000; Larson et al., 2002). However, our ability to define the equilibrium condition for these additional elements is, for the moment, very limited and there seems little benefit from the additional complexity, unless the sub-elements are the subject of interest. A simple single reservoir model, as proposed by Kraus (2002), is therefore sufficient to allow the littoral drift to be incorporated. If ASMITA is linked to an open coast beach plan model, it is possible that both input and output are prescribed, as supply or demands, and the ASMITA sediment balance equations can be solved by including the drift as an additional advective flow at the concentration needed to define the drift rate. Alternatively, if only the input is defined, it is necessary to estimate the associated output (or sediment bypassing), and the Kraus reservoir model provides a means of describing the volume change between coast and delta:

$$
\frac{\mathrm{d} V}{\mathrm{~d} t}=q s_{\text {in }}-q s_{\text {out }}, \quad q s_{\text {out }}=\left(\frac{V}{V_{e}}\right)^{n_{\mathrm{d}}} q s_{\text {in }},
$$

where $q s_{\text {in }}=$ alongshore transport into delta $=\partial q_{\mathrm{i}} \cdot c_{\mathrm{E}}$ and $q s_{\text {out }}=$ alongshore transport away from delta $=$ $\partial q_{0} \cdot c_{\text {del }}$. This simply ensures that the rate of sediment volume change in the delta is the balance of the incoming and outgoing sediment transport.

Once the input and output alongshore sediment fluxes are known, they need to be introduced into the ASMITA formulation. The simplest way to do this is treat the alongshore transport rate as an advective flow with a certain concentration of sediment. One option is to use the global equilibrium concentration, $c_{\mathrm{E}}$, to define an 'equivalent' input flow rate, $\partial q_{\mathrm{i}}$, and the concentration in the delta element, $c_{\text {del }}$, to define an 'equivalent' output flow rate, $\partial q_{\mathrm{o}}$. Alternatively, the flow rates in and out can be prescribed and the input concentration defined to give the correct input drift rate. With this approach, the output drift rate again depends on the concentration in the delta element and the defined flow rate.

Including the littoral drift presents a similar problem to the inclusion of a river flow. Inclusion of a drift at the beginning of the model run acts as a perturbation and the system adjusts to accommodate the additional flux. When simulating real systems, this can perturb the system away from the observed state. If the observed state is perceived to be close to equilibrium, it is necessary to modify the rate of change equation. This was outlined for advective flows, such as river discharge, in Part 1, leading to Eqs. (41) and (42). The approach for littoral drift is similar and for a single element leads to:

$$
\frac{\mathrm{d} V}{\mathrm{~d} t}=C\left[\left(\delta_{\mathrm{E}}+\partial q_{\mathrm{o}}\right)\left(\frac{\alpha \cdot V_{\mathrm{e}}}{V}\right)^{n}-\delta_{\mathrm{E}}-\partial q_{\mathrm{i}}\right],
$$

where $\delta_{\mathrm{E}}$ is the external horizontal exchange rate and $C$ is a coefficient derived from the system properties (see Eq. (5) in Part 1). With some re-arrangement it can be shown that $\mathrm{d} V / \mathrm{d} t=>0$ if the equilibrium volume is factored by:

$$
\alpha=\left(\frac{\delta_{\mathrm{E}}+\partial q_{\mathrm{i}}}{\delta_{\mathrm{E}}+\partial q_{\mathrm{o}}}\right)^{1 / n} .
$$


Note, however, that for the case when the equivalent flow rates in and out are equal, $\partial q_{\mathrm{i}}=\partial q_{\mathrm{o}}$, the littoral drift has no effect on the equilibrium. The matrix version of this formulation is given in the Appendix.

Some results for a typical tidal inlet are shown in Fig. 5. The model again comprises three elements, tidal flat, channel and delta and provision is made for the model to continue to run once the channel is full of sediment (zero water volume), by allowing the remaining tidal flat to exchange sediment with the tidal delta directly. A range of different rates of littoral drift are examined. As the rate of drift increases so the channel starts to infill and close up ever more rapidly. Once closed, the tidal flat and delta follow suit, until the system collapses and the littoral drift simply bypasses the inlet. This has been shown to be the response in some inlets where there is a large drift relative to the tidal exchange.
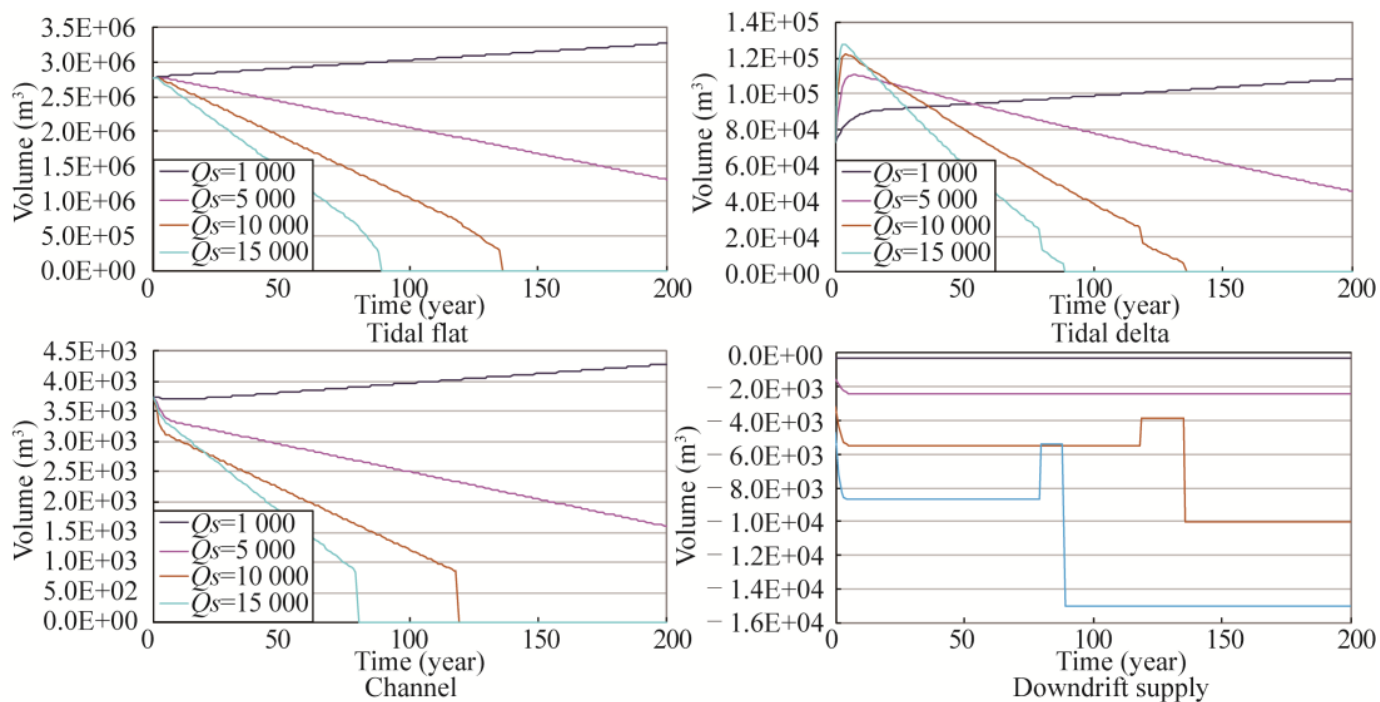

Fig. 5. Response of Pagham Harbour subject to varying rates of littoral drift ( $\left.\mathrm{m}^{3} / \mathrm{a}\right)$, together with rate of supply to the down-drift beach. As the supply rate increases so the system infills and closes more quickly and the incoming drift bypasses the inlet (negative drift rates are out of model).

\section{Waves}

Waves have the potential to influence the form of the basin internally and open coast waves will also influence the amount of sediment stored in the tidal delta. For the former, equilibrium conditions that account for the influence of waves on inlet channels and tidal flats can be defined (Townend, 2010), making use of a characteristic wind speed to describe the long-term conditions (Dal Monte and Di Silvio, 2004). For tidal deltas, the work used to define the equilibrium volume by Walton and Adams (1976) considered wave exposure when determining the parameters of the volume-prism relationship. Some more recent work by Mark (2007) has revisited this data and added data from New Zealand (Hicks and Hume, 1996) and the UK. Using the data for the Solent estuaries in the UK, Mark (2007) proposed a relationship to include wave influence based on a representative wave height 
(annual maximum $\left.H_{\mathrm{s}}\right)$ and the tidal range $\left(2 a_{\mathrm{t}}\right)$ :

$$
V=9.3 \times 10^{3}\left(\frac{H_{s_{\_} \max }}{2 a_{\mathrm{t}}} P\right)^{0.42} .
$$

At this stage, this equation should be used with caution as it is site specific and further research is needed to provide a more robust basis for estimating delta volume and extent as a function of the combined influence of wave exposure and littoral drift.

\section{Discussion}

In the previous sections, six extensions of the ASMITA model have been presented: (1) tidal pumping, (2) saltmarsh and storage element, (3) transport of mixed sediment, (4) variable area and constraints, (5) literal drift for delta and (6) the effect of waves. These extensions widen the possible applications of the model. At the same time, they also make the model more complicated. Such extensions thus have their pros and cons. Moreover, this list is not exhaustive and many other extensions of the model are possible. The question then arises as to whether such extensions, that add complexity, are useful? When is an extension of ASMITA still sensible and when would it be better to use a process-based model instead?

Before answering these questions, we recall the two essential differences between the ASMITA model and process-based models: (i) level of aggregation and (ii) implementation of the relationships for morphological equilibrium. Due to the higher level of aggregation in space and in time, there is loss of not only spatial and temporal resolution but also details of the physical processes. Therefore, the hydrodynamics are represented by aggregated parameters (e.g. tidal prism) and only tidally averaged (or residual) sediment transport can be simulated. This is why empirical relations for morphological equilibrium are required to describe the sediment exchange between water column and bed. The implementation of the relationships for morphological equilibrium does, however, have the advantage that it guaranties the model results follow the prescribed equilibrium relationships.

Most of the discussed extensions are related to the two characteristics: aggregation and morphological equilibrium. Including saltmarshes and storage elements (2) are both an extension of the schematisation. In fact, the model concept of ASMITA allows any number of morphological elements, as long as there is a relation for the morphological equilibrium available for each element. Implementing variable surface area (4) restores an aspect of the system geometry that was lost in the original aggregation. Including tidal pumping in tidal basins (1) and literal drift for delta (5) restores the lost details of physical processes due to the aggregation. Implementing the effect of waves (6) is in fact changing the prescribed relations for the morphological equilibrium. The only extension not related to aggregation nor the morphological equilibrium is the implementation of transport of mixed sediment. This extension is equally applicable to a process-based model and is thus not unique to the aggregated model ASMITA. More studies are using both types of model, to better understand the implications of incorporating mixed sediments.

Compared with the process-based models, the major advantage of the ASMITA model is that it guaranties the model results obey the prescribed relations for morphological equilibrium over the long- 
term. On this basis, any attempt to restore the lost details on geometry and/or details of physical processes should seek to keep this advantage intact. When applying the model, and particularly when making predictions of how a system might respond to imposed changes, it is important to remember that the relationships defining the equilibrium have been defined a priori but how the system approaches the equilibrium and the actual morphological form of the equilibrium state are determined by the model parameters and imposed forcing conditions. Given the speed with which simulations can be made, it is also possible to use this type of model to explore the relative influence of additional processes, or changes in the way that the geomorphology is aggregated. The model is also well suited for use in a reliability or uncertainty framework, which typically requires thousands of simulations.

Work to develop a better understanding of possible equilibrium conditions at a range of different scales is ongoing. Similarly, initial studies have highlighted the importance of mixed sediments and more work is needed to fully understand how this influences system behaviour. In estuaries and inlets with complex and rapidly evolving morphology (such as spits or banks that are rapidly prograding), the type of element may change and hence the equilibrium condition must change. This requires dynamic elements that can adapt to the prevailing conditions and this is another area that merits further research.

\section{Conclusion}

The ASMITA model has been under continuous development over the last two decades since it was first proposed in 1998. As an aggregated type of model based on prescribed equilibrium relationships, it aims to explore the bulk morphodynamic changes (in terms of volume change) of large-scale estuarine and coastal systems over relatively long-term, in contrast to the fast-scale processbased models (e.g., Delft3D) which intend to capture the details of bed-level change. Because of its simplicity and effectiveness, the ASMITA model has been used in a number of applications, showing its competence in, e.g., assessing the morphodynamic response of tidal inlets and estuaries to sea level rise and anthropogenic interventions. During the last decade, a number of subsequent extensions aiming to explore other inlet and estuary dynamics have been developed within the mass-balance framework of ASMITA, including (1) tidal pumping, (2) saltmarsh and storage element, (3) transport of mixed sediment, (4) variable area and constraints, (5) literal drift for delta and (6) the effect of waves. Adding more complexity, these extensions widen the application possibilities of the model and make the model more realistic, while retaining the advantage of obeying the prescribed morphological equilibrium over the long-term. Therefore, the ASMITA-type of models represent a different modelling philosophy, which can complement process-based models, especially when dealing with large-scale and long-term simulations.

Acknowledgements - Many colleagues have contributed to the developments reported in this paper. Contributions by Tjerk Zitman at TU Delft, Adrian Wright at ABPmer, Kate Rossington, Michiel Knaapen, and Jeremy Speerman at HR Wallingford, Davide Bonaldo at CNR-ISMAR are duly acknowledged.

\section{References}

Dal Monte, L. and Di Silvio, G., 2004. Sediment concentration in tidal lagoons. A contribution to long-term morphological modelling, J. Marine Syst., 51(1-4): 243-255. 
de Vriend, H. J., Bakker, W. T. and Bilse, D. P., 1994. A morphological behaviour model for the outer delta of mixed-energy tidal inlets, Coast. Eng., 23(3-4): 305-327.

Friedrichs, C. T., Armbrust, B. D. and de Swart, H. E., 1998. Hydrodynamics and equilibrium sediment dynamics of shallow, funnel-shaped tidal estuaries, in: J. Dronkers, M. B. A. M. Scheffers (Eds.), Physics of Estuaries and Coastal Seas, Balkema, Rotterdam, pp. 315-327.

Hicks, D. M. and Hume, T. M., 1996. Morphology and size of ebb tidal deltas at natural inlets on open-sea and pocked-bay coasts, North Island, New Zealand, J. Coastal Res., 12(1): 47-63.

Jeuken, M. C. J. L., Wang, Z. B., Keiller, D., Townend, I. H. and Liek, G. A., 2003. Morphological response of estuaries to nodal tide variation, Proceedings of the International Conference on Estuaries \& Coasts (ICEC2003), Hangzhou, China, pp. 167-173.

Jonas, P. J. and Millward, G. E., 2010. Metals and nutrients in the Severn Estuary and Bristol Channel: Contemporary inputs and distributions, Mar. Pollut. Bull., 61(1-3): 52-67.

Knaapen, M. A. F., Townend, I. H., Rossington, S. K., Fletcher, C. A. and Spearman, J., 2009. The dynamics of intertidal mudflat and salt marshes within estuaries, The Environmentalist, 84, 12-15.

Kragtwijk, N. G., Zitman, T. J., Stive, M. J. F. and Wang, Z. B., 2004. Morphological response of tidal basins to human interventions, Coast. Eng., 51(3): 207-221.

Kraus, N. C., 2000. Reservoir model of ebb-tidal shoal evolution and sand bypassing, J. Waterw. Port Coast. Ocean Eng., ASCE, 126(6): 303-313.

Kraus, N. C., 2002. Resevoir model for calculating natural and bypassing and change in volume of ebb-tidal shoals, part 1: Description, ERDC/CHL CHETN-IV-39, Vicksberg.

Krone, R. B., 1987. A method for simulating historic marsh elevations, in: N. C. Kraus (Ed.), Coastal Sediments'87, ASCE, pp. 316-323.

Larson, M., Kraus, N. C. and Hanson, H., 2002. Simulation of regional longshore sediment transport and coastal evolution - The Cascade model, Proceedings of the 28th International Conference on Coastal Engineering, Cardiff, Wales, UK, pp. 2612-2624.

Marani, M., D'Alpaos, A., Lanzoni, S., Carniello, L. and Rinaldo, A., 2007. Biologically-controlled multiple equilibria for tidal landforms and the fate of Venice lagoon, Geophys. Res. Lett., 34(L11402): 1-5.

Mark, A., 2007. Analysing the Predictive Nature of Ebb Tidal Delta Evolution Within the Model ASMITA: An Eastern Solent Case Study, University of Southampton, 1-125 pp.

Morris, J. T., 2006. Competition among marsh macrophytes by means of geomorphological displacement in the intertidal zone, Estuarine, Coastal and Shelf Science, 69(3-4): 395-402.

Morris, J. T., Sundareshwar, P. V., Nietch, C. T., Kjerfve, B. and Cahoon, D. R., 2002. Responses of coastal wetlands to rising sea level, Ecology, 83(10): 2869-2877.

Mudd, S. M., Fagherazzi, S., Morris, J. T. and Furbish, D. J., 2004. Flow, sedimentation and biomass production of a vegetated salt marsh in South Carolina: Toward a predictive model of marsh morphologic and ecologic evolution, in: S. Fagherazzi, M. Marani, L. K. Blum (Eds.), The Ecogeomorphology of Tidal Marshes, Estuarine and Coastal Studies Series, American Geophysical Union, Washington DC, pp. 165-188.

Scott, C. R., Armstrong, S., Townend, I. H., Dixon, M. and Everard, M., 2011. Lessons learned from 20 years of managed realignment and regulated tidal exchange in the UK, ICE Coastal Management 2011, pp. 1-10.

Scully, M. E. and Friedrichs, C. T., 2007. Sediment pumping by tidal asymmetry in a partially mixed estuary, $J$. Geophys. Res.-Oceans, 112(C7): 623-642.

Townend, I. H., 2008. Hypsometry of estuaries, creeks and breached sea wall sites, Proceedings of the Institution of Civil Engineers-Maritime Engineering, 161(1): 23-32. 
Townend, I. H., 2010. An exploration of equilibrium in Venice Lagoon using an idealised form model, Cont. Shelf Res., 30(8): 984-999.

Townend, I. H., Rossington, S. K., Knaapen, M. A. F. and Richardson, S., 2010a. The dynamics of intertidal mudflat and saltmarshes within estuaries, Proceedings of the 32nd International Conference on Coastal Engineering, Shanghai, China, pp. 1-10.

Townend, I. H., Scott, C. R. and Dixon, M., 2010b. Managed realignment: A coastal flood management strategy, in: G. Pender, C. R. Thorne, I. Cluckie, H. Faulkner (Eds.), Flood Risk Science and Management, Blackwell Publishing Ltd, Oxford, pp. 60-86.

Townend, I. H., Wang, Z. B., Spearman, J. and Wright, A. D., 2008. Volume and surface area changes in estuaries and tidal inlets, Proceedings of the 31st International Conference on Coastal Engineering, Hamburg, Germany, pp. 4495-4507.

Townend, I. H., Wang, Z. B., Stive, M. J. F. and Zhou, Z., 2016. Development and extension of an aggregated scale model: Part 1 - Background to ASMITA, China Ocean Eng., 30(4): 483-504.

van Goor, M. A., Zitman, T. J., Wang, Z. B. and Stive, M. J. F., 2003. Impact of sea-level rise on the morphological equilibrium state of tidal inlets, Mar. Geol., 202(3-4): 211-227.

Wang, Z. B., de Vriend, H. J., Stive, M. J. F. and Townend, I. H., 2008. On the parameter setting of semi-empirical long-term morphological models for estuaries and tidal lagoons, in: C. M. Dohmen-Janssen, S. J. M. H. Hulscher (Eds.), River, Coastal and Estuarine Morphodynamics, Taylor \& Francis, pp. 103-111.

Wang, Z. B., Jeuken, M. C. J. L., Gerritsen, H., de Vriend, H. J. and Kornman, B. A., 2002. Morphology and asymmetry of the vertical tide in the Westerschelde Estuary, Cont. Shelf Res., 22(17): 2599-2609.

Wang, Z. B., Karssen, B., Fokkink, R. J. and Langerak, A., 1998. A dynamic-empirical model for estuarine morphology, in: J. Dronkers, M.B.A.M. Scheffers (Eds.), Physics of Estuaries and Coastal Seas, Balkema, Rotterdam, pp. 279-286.

Wang, Z. B., Townend, I. H. and Stive, M. J. F., 2014. Modelling of morphological response of tidal basins to sealevel rise revisited, Proceedings of the 17th Physics of Estuaries and Coastal Seas (PECS) Conference, Porto de Galinhas, Pernambuco, Brazil.

Yu, Q., Wang, Y. W., Gao, J. H., Gao, S. and Flemming, B., 2014. Turbidity maximum formation in a well-mixed macrotidal estuary: The role of tidal pumping, J. Geophys. Res.-Oceans, 119(11): 7705-7724.

Zhou, Z., Coco, G., van der Wegen, M., Gong, Z., Zhang, C. K. and Townend, I. H., 2015. Modeling sorting dynamics of cohesive and non-cohesive sediments on intertidal flats under the effect of tides and wind waves, Cont. Shelf Res., 104, 76-91.

Zhou, Z., Roman, B. L. D. S. and Nicholls, R., 2013. An OpenMI-based combined model for alongshore sediment transport and shoreline change, Proceedings of the Institution of Civil Engineers-Maritime Engineering, 166(4): 175-186.

\section{Appendix}

The equations presented for the single element model can be conveniently written in matrix form to represent a multi-element model. Here we follow the naming convention of Kragtwijk et al. (2004) for volumes, as detailed in Part 1, and add some additional terms to make the model more general with respect to dispersion, advection and the sources of perturbations in the volume.

For a multi-element model, the variables used in this Appendix are defined as either vectors or matrices, as follows: 
$V:$ Element volumes

$\underline{S}$ : Element surface areas

$c_{\mathrm{e}}:$ Local equilibrium concentrations

$c_{\text {ext }}$ : Concentrations for fluxes into the system from the environment

$q_{\text {ext }}$ : Advective flows into the system from the environment

$\underline{c}$ : Element concentrations

Diagonal matrices:

$D$ Horizontal exchange between elements

$\boldsymbol{Q}$ Advective exchange between elements

$\boldsymbol{B}$ Expression to scale rate of change

$\underline{d}$ Expression for offset to rate of change $\underline{\gamma}:$ Volume ratios $\left(V_{k \mathrm{e}} / V_{k}\right)^{n}$

$\underline{\sigma}$ : Surface area ratios $\left(S_{k \mathrm{e}} / S_{k}\right)^{\mathrm{abs}(n)}$

$\underline{c_{\mathrm{b}}}$ : Concentration of bed

$\delta_{\text {ext }}$ : Horizontal exchange coefficients with environment

$n$ : Concentration transport exponent. positive for wet volumes and negative for sediment volumes

\section{A1. Variable Surface Area}

$\boldsymbol{W}$ Vertical exchange coefficient $w$

$S$ Surface areas

I unit or identity matrix

$\boldsymbol{M}$ unit matrix with sign of $n$

If the surface area is allowed to vary, the rate of change for the surface area $S$, is given by:

$$
\frac{\mathrm{d} \underline{S}}{\mathrm{~d} t}=\boldsymbol{F} \underline{\sigma}-\underline{e}+\underline{\Delta S}
$$

where $\boldsymbol{F}=c_{\mathrm{E}} \boldsymbol{M} \hat{\boldsymbol{W}} \boldsymbol{S}\left[\boldsymbol{I}-\left(\hat{\boldsymbol{D}}+\hat{\boldsymbol{Q}}^{\mathrm{T}}+\hat{\boldsymbol{W}} \boldsymbol{S}\right)^{-1} \hat{\boldsymbol{W}} \boldsymbol{S}\right], \underline{e}=c_{\mathrm{E}} \boldsymbol{M} \hat{\boldsymbol{W}} \boldsymbol{S}\left(\hat{\boldsymbol{D}}+\hat{\boldsymbol{Q}}^{\mathrm{T}}+\hat{\boldsymbol{W}} \boldsymbol{S}\right)^{-1} \cdot\left(\underline{\hat{\delta}_{\mathrm{ext}}}+\underline{k_{\mathrm{c}}} \cdot \hat{q}_{\mathrm{ext}}\right)$.

$\hat{\boldsymbol{D}}, \hat{\boldsymbol{Q}}, \underline{\hat{\delta}_{\mathrm{E}}}$ and $\hat{\boldsymbol{W}}$ are derived from $\boldsymbol{D}, \boldsymbol{Q}, \underline{\delta_{\mathrm{E}}}$ and $\boldsymbol{W}$ in accordance with:

$$
\hat{\delta}=\frac{\delta}{\hat{h}} ; \quad \hat{q}=\frac{q}{h} ; \quad \text { and } \quad \hat{w}=\frac{w}{h},
$$

where $\hat{h}$ is the average height of the interface between elements and $h_{j}$ is the average depth of the element the flux is into. In the equations for the surface area, $\underline{S}$, the parameter $\underline{R}$ represents the change in area for a unit change in water level and is given by $R_{k}=k_{R} \cdot L_{k} \cdot m_{\mathrm{b} k}$, where $k_{R}$ is the number of bed surfaces in the element (generally two for the two sides of the estuary), $m_{\mathrm{b} k}$ is the transverse bed slope (ie, slope is given by the ratio $1: m_{\mathrm{b}}$ ) and $L_{k}$ is the length of the $k$-th element. The term $\underline{\Delta S}$ refers to any other changes in surface area, introduced at any given time, within each element (e.g. due to reclamation). When using the ratio of element volume to tidal prism as the basis for equilibrium, the equilibrium, fixed and moving volumes are given by:

$$
\left\{\begin{array}{l}
\underline{S_{\mathrm{e}}}=\underline{\hat{\alpha}} \cdot \frac{\underline{P}}{t \underline{t r}}=\underline{\hat{\alpha}} \cdot\left(\frac{P_{\mathrm{o}}+\Delta P}{t \underline{t r}}\right) \\
\underline{S}_{\mathrm{f}}=\underline{S_{\mathrm{f} 0}}+\int \frac{\mathrm{d} \underline{S}}{\mathrm{~d} t} \mathrm{~d} t \\
\underline{S_{\mathrm{m}}}=\underline{S_{\mathrm{m} 0}}+\int \frac{\mathrm{d} \underline{S}}{\mathrm{~d} t} \mathrm{~d} t+\underline{R} \int \frac{\mathrm{d} \underline{\zeta}}{\mathrm{d} t} \mathrm{~d} t
\end{array}\right.
$$

The time varying surface area, given by Eq. (P2.3), can be used in the volume equations (Eqs. 
(P1.4) and (P1.5)) in part 1 (Townend, 2016) to obtain the combined effect of changes in surface area and volume.

\section{A2. Saltmarsh Element}

For the addition of saltmarsh elements, two additional variables are introduced: $\underline{k_{\mathrm{bm}}}$ - rate of biomass production, and $\boldsymbol{B}_{\mathrm{m}}-$ species biomass. Based on the saltmarsh biomass formulation outlined in the main text, an extra term is introduced into Eq. (P1.4) for the rate of morphological change as follows:

$$
\frac{\mathrm{d} \underline{V}}{\mathrm{~d} t}=\boldsymbol{B} \underline{\gamma}-\underline{d}-\boldsymbol{B}_{\mathrm{m}} \underline{k_{\mathrm{bm}}} \underline{V}+\underline{\Delta V},
$$

where $\boldsymbol{B}=c_{\mathrm{E}} \boldsymbol{M W S}\left[\boldsymbol{I}-\left(\boldsymbol{D}+\boldsymbol{Q}^{\mathrm{T}}+\boldsymbol{W S}\right)^{-1} \boldsymbol{W} \boldsymbol{S}\right]$, and $\underline{d}=c_{\mathrm{E}} \boldsymbol{M W} \boldsymbol{S}\left(\boldsymbol{D}+\boldsymbol{Q}^{\mathrm{T}}+\boldsymbol{W S}\right)^{-1}\left(\underline{\delta_{\mathrm{ext}}}+\underline{\boldsymbol{k}_{\mathrm{c}}} \cdot \underline{q_{\mathrm{ext}}}\right)$. The term $\boldsymbol{B}_{\mathrm{m}} k_{\mathrm{bm}} \underline{V}$ introduces the influence of the saltmarsh elements on the system due to the biomass production. The vertical exchange rates, $w$, for marsh elements are also enhanced by the influence of the biology and as a consequence the matrix $\boldsymbol{W}$ has to be updated each time step to reflect the influence of biological production. Where conditions imply sediment import to an element, then settlement will take place and the enhanced settling rate is used. However, when the equilibrium conditions imply an export of sediment from the element, enhancing the vertical exchange would imply an enhanced erosion rate. For this reason, the enhanced settling rate is only applied when the element has the potential to import sediment. This is tested at each time step by considering the ratio $V_{\mathrm{e}} / V_{\mathrm{m}}$; a value larger than one implies import and an enhanced vertical exchange is applied.

\section{A3. Tidal Pumping}

The inclusion of tidal pumping is achieved by defining an additional advective term. This has a matrix form similar to Eq. (P1.2) and modifies model Eq. (P1.4) as follows:

$$
\frac{\mathrm{d} \underline{V}}{\mathrm{~d} t}=\frac{1}{\underline{c_{\mathrm{b}}}}(\boldsymbol{B} \underline{\gamma}-\underline{d})+\underline{\Delta V},
$$

where $\boldsymbol{B}=c_{\mathrm{E}} \boldsymbol{M W S}\left[\boldsymbol{I}-\left(\boldsymbol{D}+\boldsymbol{Q}^{\mathrm{T}}+\boldsymbol{Q}_{\mathrm{tp}}^{\mathrm{T}}+\boldsymbol{W} \boldsymbol{S}\right)^{-1} \boldsymbol{W} \boldsymbol{S}\right]$, and

$$
\underline{d}=c_{\mathrm{E}} \boldsymbol{M} \boldsymbol{W S}\left(\boldsymbol{D}+\boldsymbol{Q}^{\mathrm{T}}+\boldsymbol{Q}_{\mathrm{tp}}^{\mathrm{T}}+\boldsymbol{W S}\right)^{-1}\left(\underline{\delta_{\mathrm{ext}}}+\underline{q_{\mathrm{tp} \_x t}}+\underline{k_{\mathrm{c}}} \cdot \underline{q_{\mathrm{ext}}}\right) .
$$

$\boldsymbol{Q}_{\mathrm{tp}}$ is the matrix that describes equivalent flow due to tidal pumping, and has the same form as the advection matrix, $\boldsymbol{Q}$, defined in Eq. (P1.2) and $q_{\text {tp_ext }}$ is the tidal pumping input from the external environment.

\section{A4. Littoral Drift}

For a multi-element model, the exchanges between elements are handled by a matrix summation of the horizontal exchanges and only exchanges with the external environment need to be handled explicitly, see Eqs. (P1.1)-(P1.4). Including littoral drift requires that $\boldsymbol{Q}_{\mathrm{s}}$ is added to incorporate the export of sediment from the delta due to alongshore transport and is a matrix for $\partial q_{0}$ : 


$$
\frac{\mathrm{d} \underline{V}}{\mathrm{~d} t}=\frac{1}{\underline{c_{\mathrm{b}}}}(\boldsymbol{B} \underline{\gamma}-\underline{d})+\underline{\Delta V},
$$

where, $\boldsymbol{B}=c_{\mathrm{E}} \boldsymbol{M} \boldsymbol{W} \boldsymbol{S}\left[\boldsymbol{I}-\left(\boldsymbol{D}+\boldsymbol{Q}^{\mathrm{T}}+\boldsymbol{Q}_{\mathrm{s}}^{\mathrm{T}}+\boldsymbol{W} \boldsymbol{S}\right)^{-1} \boldsymbol{W S}\right]$, and

$$
\underline{d}=c_{\mathrm{E}} \boldsymbol{M} \boldsymbol{W} \boldsymbol{S}\left(\boldsymbol{D}+\boldsymbol{Q}^{\mathrm{T}}+\boldsymbol{Q}_{\mathrm{s}}^{\mathrm{T}}+\boldsymbol{W S}\right)^{-1}\left(\underline{\delta_{\mathrm{ext}}}+\underline{k_{\mathrm{c}}} \cdot \underline{q_{\mathrm{ext}}}+\underline{\partial q_{i}}\right) .
$$

The correction to the equilibrium volume is then given by:

$$
\underline{V_{\mathrm{e}}}=\underline{V_{\mathrm{e} 0}}\left(\boldsymbol{B}^{-1} \cdot \underline{d}\right)^{1 / n} \text {. }
$$

